\title{
Endoscopic pH monitoring for patients with suspected or refractory gastroesophageal reflux disease
}

\author{
Brian G Turner $M D^{1}$, John R Saltzman $M D^{1}$, Ling Hua $B A^{1}$, Rie Maurer $M A^{1}$, Natan Feldman $M D^{1}$, \\ David L Carr-Locke $M D^{1}$, Robert Burakoff $M D^{1}$, Julia J Liu MD²
}

\begin{abstract}
BG Turner, JR Saltzman, L Hua, et al. Endoscopic pH monitoring for patients with suspected or refractory gastroesophageal reflux disease. Can J Gastroenterol 2007; 21(11):737-741.
\end{abstract}

BACKGROUND: Wireless $\mathrm{pH}$ studies can offer prolonged $\mathrm{pH}$ monitoring, which may potentially facilitate the diagnosis and management of patients with gastroesophageal reflux disease (GERD). The aim of the present study was to evaluate the detection rate of abnormal esophageal acid exposure using prolonged $\mathrm{pH}$ monitoring in patients with suspected or refractory GERD symptoms.

METHODS: Patients undergoing prolonged ambulatory $\mathrm{pH}$ studies for the evaluation of GERD-related symptoms were assessed. Patients with a known diagnosis of GERD were tested on medical therapy, while patients with suspected GERD were tested off therapy. The wireless $\mathrm{pH}$ capsules were placed during upper endoscopy $6 \mathrm{~cm}$ above the squamocolumnar junction.

RESULTS: One hundred ninety-one patients underwent a total of $198 \mathrm{pH}$ studies. Fifty ambulatory pH studies (25\%) were excluded from the analysis: 27 patients (14\%) had insufficient data capture (less than $18 \mathrm{~h}$ on at least one day of monitoring), 15 patients had premature capsule release (7\%), seven were repeat studies $(3.5 \%)$ and one had intolerable pain requiring capsule removal $(0.5 \%)$. There were 115 patients undergoing $\mathrm{pH}$ studies who were off medication, and 33 patients were on therapy. For the two groups of patients, results were as follows: $32(28 \%)$ and $22(67 \%)$ patients with normal studies on both days; $58(50 \%)$ and five $(15 \%)$ patients with abnormal studies on both days; $18(16 \%)$ and three $(9 \%)$ patients with abnormal studies on day 1 only; and seven (6\%) and three (9\%) patients with abnormal studies on day 2 only, respectively.

CONCLUSIONS: Prolonged $48 \mathrm{~h} \mathrm{pH}$ monitoring can detect more abnormal esophageal acid exposure but is associated with a significant rate of incomplete studies.

Key Words: Ambulatory pH monitoring; Endoscopy; Gastroesophageal reflux disease; Treatment

\section{Surveillance endoscopique du $\mathrm{pH}$ chez des patients souffrant de reflux gastro-oesophagien présumé ou réfractaire}

CONTEXTE : La pHmétrie sans fil permet une surveillance prolongée du $\mathrm{pH}$ et peut ainsi faciliter le diagnostic et le traitement du reflux gastrooesophagien (RGO). La présente étude avait pour but d'évaluer le taux de détection de l'exposition anormale à l'acidité oesophagienne par une surveillance prolongée du $\mathrm{pH}$ chez des patients présentant des symptômes de RGO présumé ou de RGO réfractaire.

MÉTHODE : Des patients ont été soumis à une mesure prolongée et ambulatoire du pH pour une évaluation de symptômes liés au RGO. Ceux chez qui un diagnostic de RGO avait déjà été posé ont fait l'objet d'évaluation en cours de traitement, tandis que ceux chez qui il y avait présomption de RGO ont fait l'objet d'évaluation avant l'instauration du traitement. Les capsules de mesure du $\mathrm{pH}$ sans fil ont été mises en place au cours d'une endoscopie digestive haute, à une hauteur de $6 \mathrm{~cm}$ audessus de la jonction squamo-columnaire.

RÉSULTATS : Un total de 198 mesures du pH a été effectué chez 191 patients. Cinquante mesures ambulatoires (25\%) ont été écartées de l'analyse : 27 (14\%) pour insuffisance de données (moins de $18 \mathrm{~h}$ sur au moins une journée de surveillance); 15 (7\%) pour libération prématurée de la capsule; 7 (3,5 \%) pour reprise de l'exploration; 1 (0,5\%) pour douleur intolérable nécessitant le retrait de la capsule. Cent quinze sujets ne prenaient pas de médicaments alors que 33 étaient soumis à un traitement. Voici les résultats enregistrés respectivement dans les deux groupes de patients : $32(28 \%)$ et $22(67 \%)$ sujets ont obtenu des résultats normaux au cours des deux journées; $58(50 \%)$ et $5(15 \%)$ sujets, des résultats anormaux au cours des deux journées; 18 (16\%) et 3 (9\%) sujets, des résultats anormaux au cours de la première journée seulement; 7 (6\%) et $3(9 \%)$ sujets, des résultats anormaux au cours de la deuxième journée seulement.

CONCLUSION : La surveillance prolongée du pH sur 48 heures a permis de détecter un plus grand nombre de cas d'exposition anormale à l'acidité oesophagienne, mais elle a été associée à un taux relativement élevé d'exploration incomplète.

$\mathrm{T}$ he diagnosis of gastroesophageal reflux disease (GERD) can be challenging due to the wide spectrum of clinical presentations, particularly extraesophageal manifestations $(1,2)$. Conventional esophageal $\mathrm{pH}$ monitoring is performed using a transnasal catheter that is placed at $5 \mathrm{~cm}$ above the manometrically determined lower esophageal sphincter (3).

The esophageal $\mathrm{pH}$ is recorded for $24 \mathrm{~h}$. Ambulatory esophageal acid exposure is the gold standard for the diagnosis of GERD, with good sensitivity and specificity (4-6).

A wireless $\mathrm{pH}$ monitoring system, introduced in 2000 , allows for prolonged $48 \mathrm{~h}$ monitoring (7). One advantage of the wireless system is the avoidance of the transnasal catheter,

\footnotetext{
${ }^{1}$ Division of Gastroenterology, Brigham and Women's Hospital, Boston, Massachusetts, USA; ${ }^{2}$ Division of Gastroenterology, University of Alberta Hospital, Edmonton, Alberta

Correspondence: Dr Julia J Liu, Division of Gastroenterology, University of Alberta Hospital, 1-10 Zeidler Ledcor Centre,

University of Alberta Campus, Edmonton, Alberta T6R 2C1. Telephone 780-492-6874, fax 780-492-7115, e-mail julia.liu@ualberta.ca Received for publication January 23, 2007. Accepted March 17, 2007
} 
which results in less interference of patient's daily activities of living and improved patient satisfaction (8). Moreover, the wireless $\mathrm{pH}$ capsule system permits longer, less intrusive esophageal $\mathrm{pH}$ monitoring (9) and thus, may have the potential to improve the diagnostic yield of abnormal esophageal acid exposure in patients with symptoms related to GERD. The aim of the present study was to evaluate the detection rate of abnormal esophageal acid exposure using the wireless, prolonged $\mathrm{pH}$ monitoring system. We hypothesized that a $48 \mathrm{~h} \mathrm{pH}$ monitoring study would increase the number of subjects having evidence of GERD with abnormal amounts of acid exposure when compared with a $24 \mathrm{~h} \mathrm{pH}$ monitoring period.

\section{METHODS}

\section{Study design}

All patients undergoing prolonged ambulatory $\mathrm{pH}$ studies to evaluate GERD-related symptoms between June 2003 and December 2005 in the Brigham and Women's Hospital (Boston, Massachusetts, USA) were enrolled in the study. The hospital is a tertiary referral centre for patients with GERDrelated symptoms in the area. The study was approved by the Partners Human Research Committee. Patients' symptoms included typical and atypical symptoms of GERD, or persistent GERD-related symptoms despite medical therapy. Patients with planned antireflux procedures were also evaluated. Patients with suspected GERD-related symptoms were tested off medical therapy, while patients with persistent GERD symptoms despite medical therapy and those with planned antireflux procedures, were tested on medical therapy. Before testing, patients were instructed to take nothing by mouth for at least $6 \mathrm{~h}$ before the procedure. No dietary or activity restrictions were imposed during the monitoring period. Results for patients who were off medications are presented separately from those on therapy.

\section{Placement of the Bravo $\mathrm{pH}$ capsule (Medtronic Inc, USA)} All wireless Bravo $\mathrm{pH}$ capsules were placed during upper endoscopy. Patients were sedated with midazolam and fentanyl for the upper endoscopy. After direct visualization of the squamocolumnar junction, the endoscope was removed and the capsule was placed $6 \mathrm{~cm}$ above the endoscopically determined squamocolumnar junction. In patients with known Barrett's esophagus, the location of the diaphragmatic hiatus was used as the squamocolumnar junction. Immediately after placement, capsule location and function was confirmed by obtaining a $\mathrm{pH}$ value of more than 4 on the $\mathrm{pH}$ monitor and/or visual reinspection.

\section{Data collection for the $\mathrm{pH}$ study}

Patients were instructed to resume daily activities of living and a regular diet. The patients were instructed to keep the monitoring unit within $1 \mathrm{~m}$ of their body at all times to ensure optimal data transmission and recording for the $48 \mathrm{~h}$ period. Reflux-related symptoms were recorded with the $\mathrm{pH}$ monitoring unit by pressing buttons corresponding to chest pain, heartburn and regurgitation symptoms. Patients were also asked to keep a diary that recorded food intake, medications, body position and symptoms. The monitor was returned after $48 \mathrm{~h}$. The $\mathrm{pH}$ data were then downloaded to the computer unit and analyzed with PolygramNet software (Medtronic Inc, USA).

\section{Definition of abnormal $\mathrm{pH}$ study}

An abnormal $\mathrm{pH}$ study was defined as the total percentage of time that an esophageal $\mathrm{pH}$ of less than 4.0 was greater than $4 \%$; an abnormal supine reflux was defined as an esophageal $\mathrm{pH}$ of less than 4.0 in the supine position of $1.2 \%$ or greater over any $24 \mathrm{~h}$ monitoring period; and abnormal upright reflux was defined as an esophageal $\mathrm{pH}$ of less than 4.0 in the upright position for $6.3 \%$ or greater over any $24 \mathrm{~h}$ monitoring period. The Johnson and DeMeester score (10) was calculated using six criteria: per cent of total time that the $\mathrm{pH}$ was less than 4.0; per cent of upright time that $\mathrm{pH}$ was less than 4.0; per cent of supine time that $\mathrm{pH}$ was less than 4.0; total number of reflux events; number of reflux episodes longer than $5 \mathrm{~min}$; and the longest episode of reflux (in minutes). A total composite score of more than 14.72 , using these criteria, was considered to be a pathological reflux.

\section{Analysis of the $\mathrm{pH}$ results}

All $\mathrm{pH}$ tracings were reviewed and studies where esophageal $\mathrm{pH}$ was consistently less than 4.0 for over $30 \mathrm{~min}$, followed by a persistent rise in $\mathrm{pH}$ to above 4.0 , were excluded due to presumed premature capsule release. The assumption was that the released Bravo capsule had dislodged into the stomach and subsequently passed into the small bowel. A study with fewer than $18 \mathrm{~h}$ of data collection over any of two consecutive $24 \mathrm{~h}$ periods was also excluded for insufficient data capture. The overall number of patients with disease and the day-to-day variability of $\mathrm{pH}$ measurements were assessed in the two consecutive $24 \mathrm{~h}$ periods. A patient was considered to have day-today variability when pathological $\mathrm{pH}$, as defined above, was present on day 1 of monitoring and absent on day 2, or vice versa. We also investigated abnormal acid exposure in the upright and supine positions with regard to symptoms and esophageal $\mathrm{pH}$.

\section{Statistical analysis}

SAS version 8.02 (SAS Institute Inc, USA) was used to perform data analysis. A McNemar test was performed to evaluate the discordance between day 1 and day 2 esophageal acid exposure by testing the null hypothesis of marginal homogeneity. $\mathrm{P}<0.05$ was considered to be significant.

\section{RESULTS}

There were 191 patients who had 198 wireless $\mathrm{pH}$ capsules placed during the study period of June 2003 to December 2005. Fifty ambulatory $\mathrm{pH}$ studies (25\%) were excluded from the analysis due to the following reasons: 27 patients (14\%) had insufficient data capture (less than $18 \mathrm{~h}$ on at least one day of monitoring), 15 patients ( $7 \%$ ) had premature capsule release, seven were repeat studies $(3.5 \%)$ and one had intolerable pain requiring capsule removal $(0.5 \%)$.

There were 150 studies performed in patients with suspected GERD symptoms who were off medical therapy. Thirtyfive studies were excluded from analysis due to the following reasons: 20 patients (14\%) had insufficient data capture, 10 patients $(7 \%)$ had premature capsule release and five patients had repeat studies. A total of 115 patients with a mean $( \pm$ SD) age of $50 \pm 13$ years had adequate studies for evaluation and were included in the analysis. There were 76 women $(66 \%)$ and 39 men $(34 \%)$.

There were 48 studies performed on patients with refractory GERD symptoms who were on medical therapy. 
Fifteen patients were excluded from analysis due to the following reasons: seven patients $(15 \%)$ had insufficient data capture, five patients $(10 \%)$ had premature capsule release, two had a repeat $\mathrm{pH}$ study $(4 \%)$ and one had early removal of the capsule due to severe pain (2\%). A total of 33 patients with a mean age of $52 \pm 14$ years had adequate studies for evaluation and were included in the analysis. There were 26 women $(79 \%)$ and seven men $(21 \%)$. Of those 33 patients, 13 patients $(39 \%)$ were on once-daily proton pump inhibitor therapy, with two of 13 also using nocturnal $\mathrm{H}_{2}$ blockers, 17 patients $(52 \%)$ were on twice-daily proton pump inhibitor therapy (one was also on a nocturnal $\mathrm{H}_{2}$ blocker), and two patients (6\%) were on three times per day proton pump inhibitor therapy. One patient was on a twicedaily $\mathrm{H}_{2}$ blocker $(3 \%)$ due to intolerance of proton pump inhibitors.

Day-to-day variability in esophageal acid exposure

The day-to-day variability in esophageal acid exposure was evaluated by examining the total percentage of time that $\mathrm{pH}$ was less than 4.0. In the 115 patients who were off medications and undergoing $\mathrm{pH}$ studies to establish the diagnosis of GERD, 58 had abnormal studies on both days, 32 had normal studies on both days, 18 had an abnormal study on day 1 and a normal study on day 2, while seven had a normal study on day 1 but an abnormal study on day 2 (Table 1 ). There were 25 patients (22\%) with abnormal acid exposure on only one of the two days monitored. Seventy-six patients (66\%) had abnormal acid exposure on day 1 and 65 had abnormal acid exposure (57\%) on day 2 (Table 1 ). There was a $22 \%$ discordance between day 1 and day 2 total esophageal acid exposure $(\mathrm{P}=0.03)$.

To determine the source of variability in esophageal acid exposure, we examined abnormal esophageal acid exposure in the supine position for patients who were off medications. There were 41 patients with abnormal esophageal acid exposure in the supine position on both days, 49 patients with normal supine acid exposure on both days, 13 patients with an abnormal supine acid exposure on day 1 but a normal supine acid exposure on day 2 , and 12 patients with a normal supine acid exposure on day 1 but an abnormal supine acid exposure on day 2 . There were 54 patients (47\%) with abnormal supine acid exposure on day 1 and 53 patients (46\%) with abnormal supine acid exposure on day 2 (Table 1 ). There was a $22 \%$ discordance between day 1 and day 2 supine acid exposure $(\mathrm{P}=0.84)$. Therefore, the total day-to-day variability in esophageal acid exposure did not appear to be due to changes in supine esophageal acid exposure.

Abnormal esophageal acid exposure in the upright position was evaluated for the 115 patients who were off medical therapy. There were 47 patients with abnormal esophageal acid exposure in the upright position on both days, 44 patients with normal upright acid exposure on both days, 20 patients with an abnormal upright acid exposure on day 1 but a normal upright acid exposure on day 2, and four patients with a normal upright acid exposure on day 1 but an abnormal upright acid exposure on day 2. Overall, there were 67 patients $(58 \%)$ with an abnormal upright acid exposure on day 1 and 51 patients (44\%) with an abnormal upright acid exposure on day 2 . On day 1 , the mean per cent time upright $\mathrm{pH}$ was less than 4.0 was $9.6 \pm 8.3 \%$, and on day 2 it was $7.6 \pm 7.5 \%$. There was a discordance of $21 \%$ between day 1 and day 2 upright esophageal acid exposures
TABLE 1

Esophageal acid exposure variability for diagnosis of
gastroesophageal reflux disease: Number of patients with
positive (abnormal) versus negative (normal) Bravo*
studies

studies

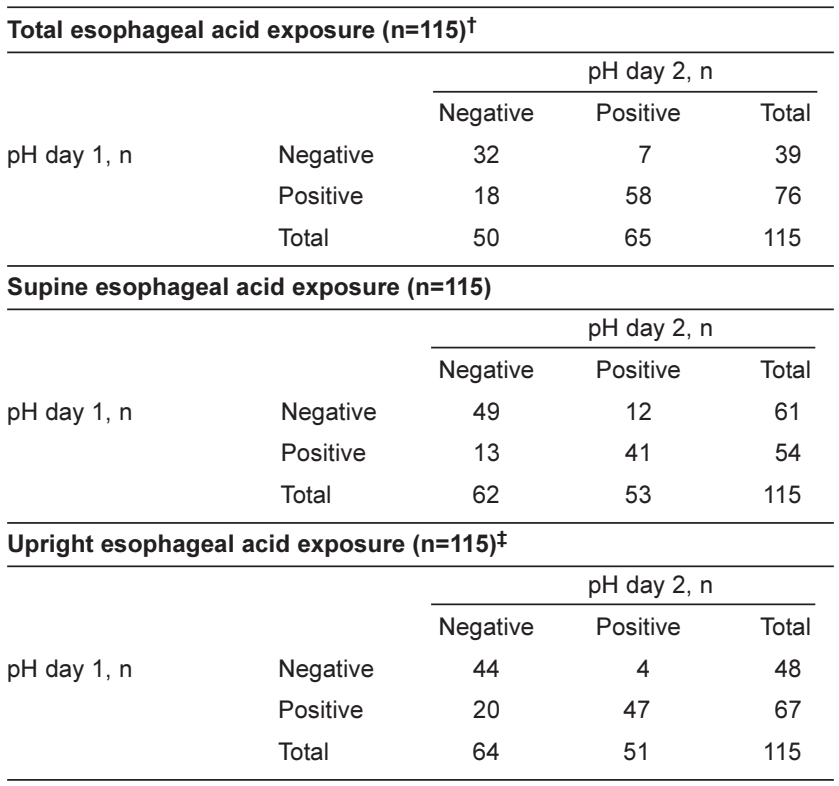

${ }^{*}$ Bravo $\mathrm{pH}$ capsule (Medtronic Inc, USA); ${ }^{\dagger} P=0.03$, McNemar test; ${ }^{\ddagger} P=0.001$, McNemar test

$(\mathrm{P}=0.001)$ and thus, differences in upright esophageal acid exposures accounted for the total day-to-day variability seen in those patients.

For the 33 patients undergoing $\mathrm{pH}$ monitoring performed with refractory GERD symptoms on therapy, five patients had abnormal studies on both days, 22 patients had normal studies on both days, three had an abnormal study on day 1 and a normal study on day 2, while three had a normal study on day 1 and an abnormal study on day 2 (Table 2). There were six patients (18\%) with abnormal acid exposure on only one of the two days monitored. Eight patients (24\%) had abnormal acid exposure on day 1 and eight patients (24\%) had abnormal acid exposure on day 2 . The $18 \%$ discordance between day 1 and day 2 total esophageal acid exposures was not significant $(\mathrm{P}=1.0)$.

\section{DISCUSSION}

The purpose of our study was to evaluate the detection rate of abnormal esophageal acid exposure using the wireless, prolonged $\mathrm{pH}$ monitoring system and compare it to a $24 \mathrm{~h} \mathrm{pH}$ monitoring study. Our data showed that prolonged $48 \mathrm{~h} \mathrm{pH}$ monitoring was able to detect more abnormal esophageal acid exposure for patients with suspected GERD-related symptoms with a significant discordance (22\%) between day 1 and day 2 monitoring. In patients with refractory GERD symptoms, the discordance between day 1 and day 2 esophageal acid exposure was $18 \%$. Therefore, prolonged $48 \mathrm{~h} \mathrm{pH}$ monitoring may have clinical advantages over a $24 \mathrm{~h} \mathrm{pH}$ study.

In patients with suspected GERD symptoms, prolonged $\mathrm{pH}$ monitoring clearly improves the diagnostic yield of the test. However, in patients with refractory symptoms, the difference in the esophageal acid exposure was not significant. This may be due to the small sample size of our refractory symptom 


\section{TABLE 2}

Esophageal acid exposure variability for refractory gastroesophageal reflux disease symptoms: Number of patients with positive (abnormal) versus negative (normal) Bravo* studies

Total esophageal acid exposure $(n=33)$

\begin{tabular}{|c|c|c|c|c|}
\hline \multirow{5}{*}{$\mathrm{pH}$ day $1, \mathrm{n}$} & & \multicolumn{3}{|c|}{$\mathrm{pH}$ day $2, \mathrm{n}$} \\
\hline & & Negative & Positive & Total \\
\hline & Negative & 22 & 3 & 25 \\
\hline & Positive & 3 & 5 & 8 \\
\hline & Total & 25 & 8 & 33 \\
\hline \multicolumn{5}{|c|}{ Supine esophageal acid exposure $(n=33)$} \\
\hline \multirow{5}{*}{$\mathrm{pH}$ day $1, \mathrm{n}$} & & \multicolumn{3}{|c|}{$\mathrm{pH}$ day $2, \mathrm{n}$} \\
\hline & & Negative & Positive & Total \\
\hline & Negative & 25 & 3 & 28 \\
\hline & Positive & 3 & 2 & 5 \\
\hline & Total & 28 & 5 & 33 \\
\hline \multicolumn{5}{|c|}{ Upright esophageal acid exposure $(n=33)$} \\
\hline \multirow{5}{*}{$\mathrm{pH}$ day $1, \mathrm{n}$} & & \multicolumn{3}{|c|}{$\mathrm{pH}$ day $2, \mathrm{n}$} \\
\hline & & Negative & Positive & Total \\
\hline & Negative & 23 & 2 & 25 \\
\hline & Positive & 5 & 3 & 8 \\
\hline & Total & 28 & 5 & 33 \\
\hline
\end{tabular}

${ }^{*}$ Bravo $\mathrm{pH}$ capsule, Medtronic Inc, USA

patient population rather than a true lack of improvement in the diagnostic yield for these patients.

We observed more abnormal acid exposures on day 1 (66\%) than day $2(57 \%)$. This could be due to stress related to the placement of the device, as well as anesthetics and anxiolytics required for capsule placement, all of which could reduce the lower esophageal sphincter pressure. Thus, some of the abnormalities noted on day 1 may, in fact, not be due to pathological GERD. This difference was noted in a previous report by Bhat et al (11). It further suggests that prolonged data collection may be helpful in establishing the diagnosis of GERD.

For patients with refractory GERD symptoms, 11 of 33 patients (33\%) had abnormal esophageal acid exposure despite taking acid-reducing medications, suggesting inadequate acid suppression for those patients. This information is

\section{REFERENCES}

1. Kahrilas PJ, EM Quigley. Clinical esophageal $\mathrm{pH}$ recording: A technical review for practice guideline development. Gastroenterology 1996;110:1982-96.

2. Quigley EM. 24-h pH monitoring for gastroesophageal reflux disease: Already standard but not yet gold? Am J Gastroenterol 1992;87:1071-5.

3. Demeester TR, Johnson LF, Joseph GJ, Toscano MS. Patterns of gastroesophageal reflux in health and disease. Ann Surg 1976;184:459-70.

4. Jamieson JR, Stein HJ DeMeester TR, et al. Ambulatory 24-h esophageal $\mathrm{pH}$ monitoring: Normal values, optimal thresholds, specificity, sensitivity, and reproducibility. Am J Gastroenterol 1992;87:1102-11.

5. Fuchs KH, DeMeester TR, Albertucci M. Specificity and sensitivity of objective diagnosis of gastroesophageal reflux disease. Surgery 1987;102:575-80.

6. DeVault KR, Castell DO. Guidelines for the diagnosis and treatment of gastroesophageal reflux disease. Practice Parameters particularly helpful for the management of these patients' symptoms. Therefore, prolonged $\mathrm{pH}$ monitoring may aid in the treatment of refractory GERD symptoms by detecting patients with inadequate acid suppression.

In a recent study (12) examining day-to-day variability of esophageal acid exposure with the Bravo $\mathrm{pH}$ capsule, day-today variability was seen in $27 \%$ of 190 patients in three tertiary care centres on and off acid suppressive therapy. Differences in capsule placement techniques among the study centres, ie, manometrically or endoscopically placed capsules, could have accounted for the higher variability in the report.

A review of the literature did not reveal conventional transnasal catheter detachment as a major limitation to $\mathrm{pH}$ measurement. In one study (8) involving 50 patients, one-half of the patients underwent wireless capsule placement and onehalf underwent traditional $\mathrm{pH}$ probe placement; in the conventional group, one patient (4\%) removed the catheter. One author (13), having performed over 5000 transnasal catheter $\mathrm{pH}$ studies, suggests that the inability to obtain adequate $\mathrm{pH}$ data occurs in approximately $5 \%$ to $10 \%$ of patients, although it is unclear what percentage is due to insufficient data capture or catheter removal.

The failure rate reported in the literature is $2 \%$ to $11 \%$ to wireless $\mathrm{pH}$ monitoring $(9,11,12,14,15)$. However, in our study, the failure rate was $21 \%$, due to a combination of insufficient data capture (14\% [27 of 198]) and premature capsule release (7\% [15 of 198]). The rate of premature capsule release was $9 \%$ for the first 100 studies and $6 \%$ for the remaining 98 studies. All patients were instructed to keep the monitoring unit within $1 \mathrm{~m}$ of their body, although many patients had prolonged periods where the $\mathrm{pH}$ data were not recorded. Therefore, future improvements in the technology are needed to reduce the rate of premature capsule release and improve the rate of data capture.

\section{CONCLUSION}

Prolonged $48 \mathrm{~h}$ wireless esophageal $\mathrm{pH}$ monitoring may improve the diagnostic yield for detecting GERD-related symptoms. It may improve the management of patients with day-to-day variability in their esophageal acid exposure by detecting more episodes. However, there is a significant rate of incomplete studies due to capsule detachment, and insufficient data capture and recording.

Committee of the American College of Gastroenterology. Arch Intern Med 1995;155:2165-73.

7. Chotiprashidi P, Lie J, Carpenter S, et al, for the Technology Assessment Committee, American Society for Gastrointestinal Endoscopy. ASGE Technology Status Evaluation Report: Wireless esophageal $\mathrm{pH}$ monitoring system. Gastrointest Endosc 2005;62:485-7.

8. Wong WM, Bautista J, Dekel, et al. Feasibility and tolerability of transnasal/per-oral placement of the wireless $\mathrm{pH}$ capsule vs. traditional 24-h oesophageal $\mathrm{pH}$ monitoring - a randomized trial. Aliment Pharmacol Ther 2005;21:155-63.

9. Pandolfino JE, Richter JE, Ours T, Guardino JM, Chapman J, Kahrilas PJ. Ambulatory esophageal pH monitoring using a wireless system. Am J Gastroenterol 2003:98:740-9.

10. Johnson LF, DeMeester TR. Development of the 24-hour intraesophageal $\mathrm{pH}$ monitoring composite scoring system. J Clin Gastroenterol 1986;8(Suppl 1):52-8. 
11. Bhat YM, McGrath KM, Bielefeldt K. Wireless esophageal pH monitoring: New technique means new questions. J Clin Gastroenterol 2006;40:116-21.

12. Tseng D, Risvi AZ, Fennerty MB, et al. Forty-eight-hour $\mathrm{pH}$ monitoring increases sensitivity in detecting abnormal esophageal acid exposure. J Gastrointest Surg 2005;9:1043-51;

discussion 1051-2.

13. DeVault, KR. Catheter-based $\mathrm{pH}$ monitoring: Use in evaluation of gastroesophageal reflux disease symptoms (on and off therapy). Gastrointest Endosc Clin N Am 2005;15:289-306.

14. Ahlawat SK, Novak DJ, Williams DC, Maher KA, Barton F, Benjamin SB. Day-to-day variability in acid reflux patterns using the BRAVO $\mathrm{pH}$ monitoring system. J Clin Gastroenterol 2006;40:20-4.

15. Ward EM, Devault KR, Bouras EP, et al. Successful oesophageal $\mathrm{pH}$ monitoring with a catheter-free system. Aliment Pharmacol Ther 2004;19:449-54. 


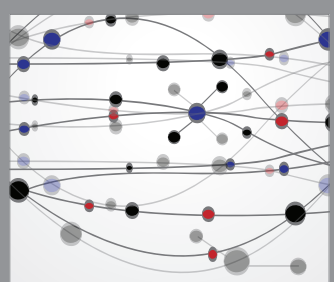

The Scientific World Journal
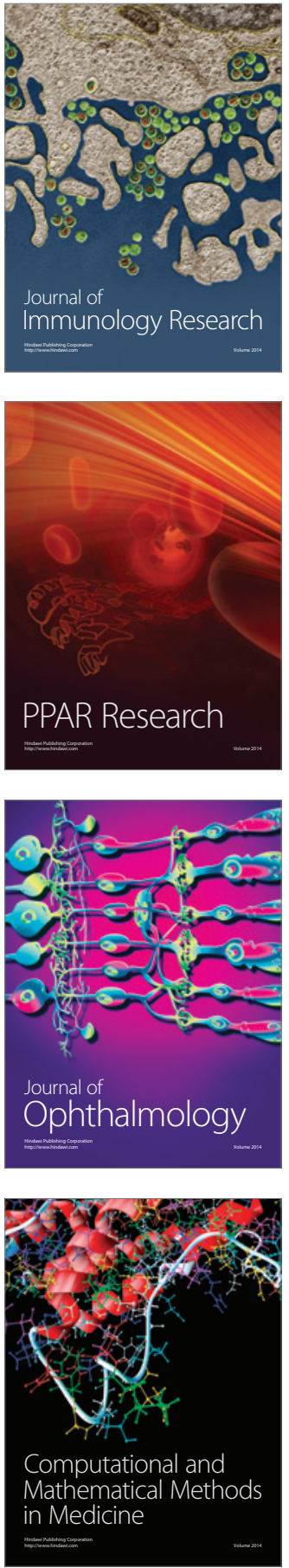

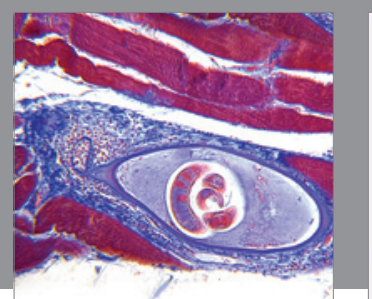

Gastroenterology Research and Practice

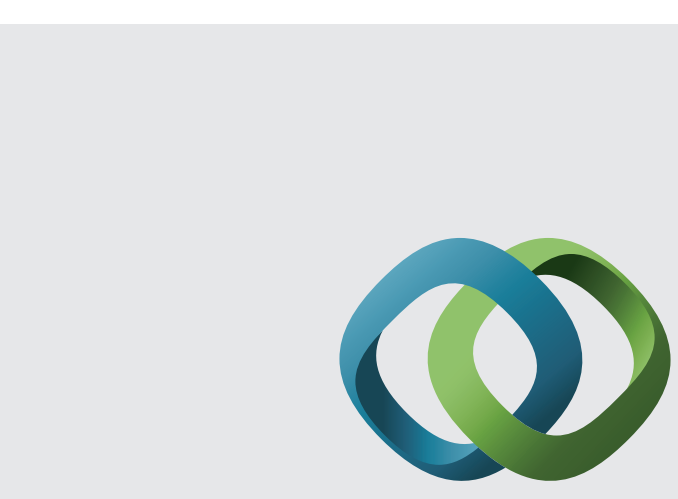

\section{Hindawi}

Submit your manuscripts at

http://www.hindawi.com
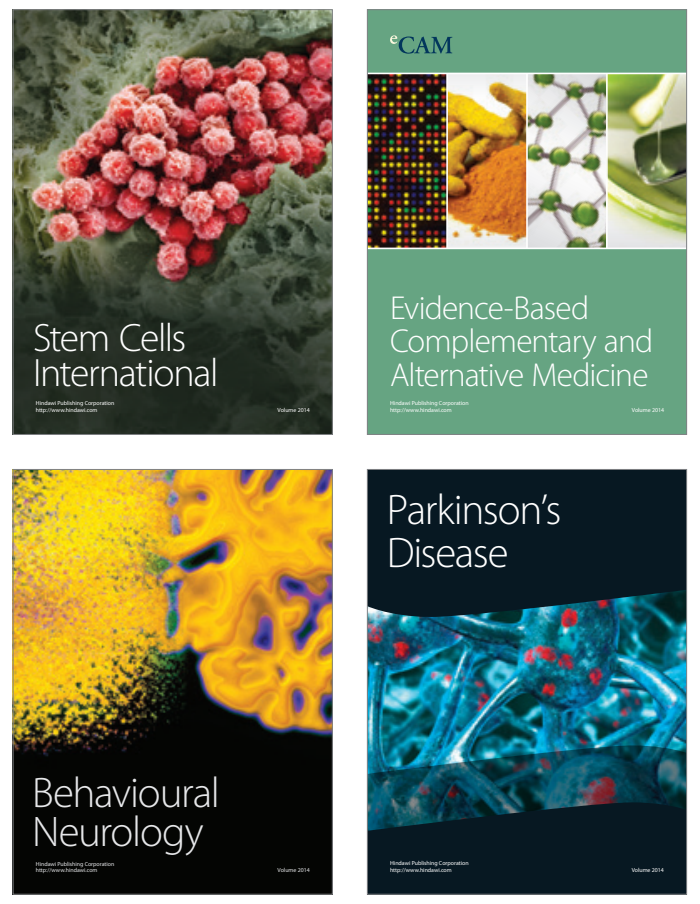
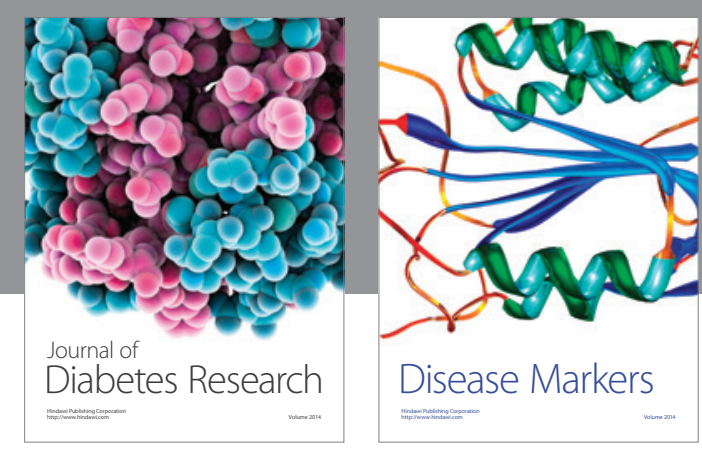

Disease Markers
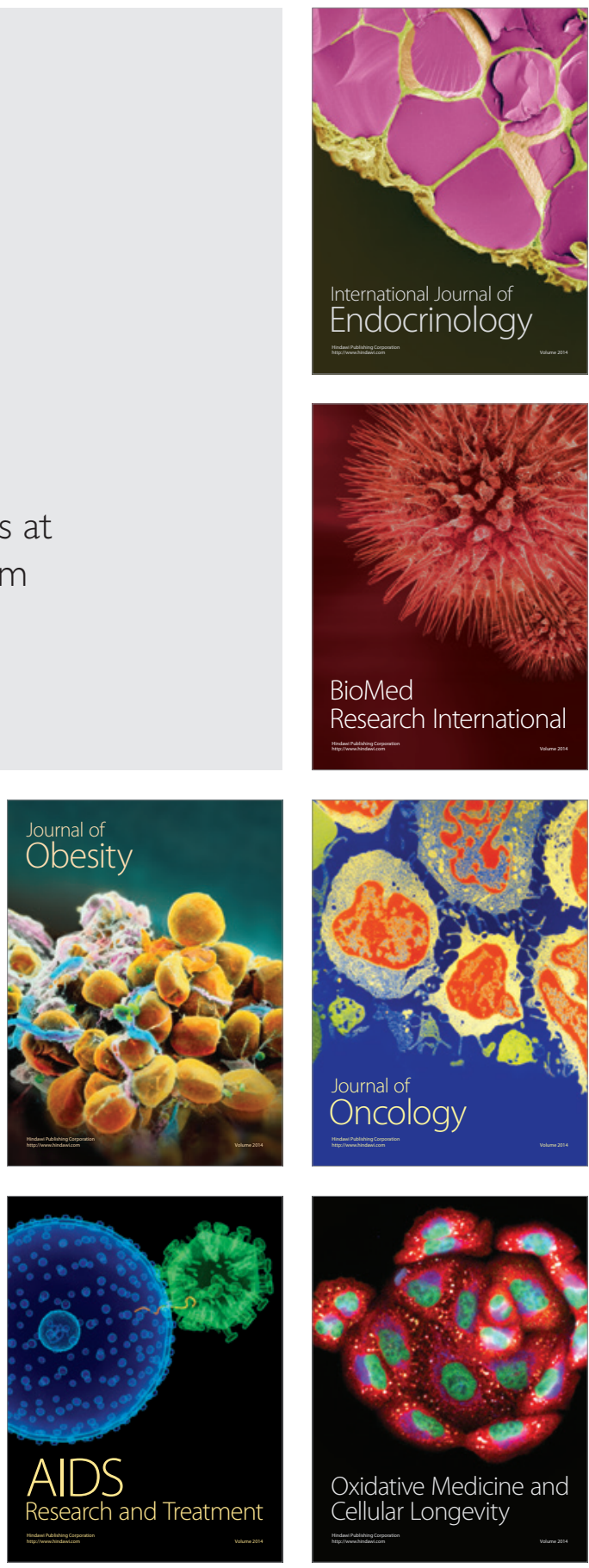